\title{
Mapping globalization: A conversation between a filmmaker and a cartographer
}

\begin{abstract}
:
This paper is an edited version of a written dialogue that took place between the fall of 2008 and the summer of 2009 between a filmmaker (Amelia Bryne) and a cartographer (Sébastien Caquard) around the issue of representing globalization. In these conversations we define some of the key means for representing globalization in both mapmaking and filmmaking discussing local/global, strategic/tactical, data/narrative, and unique/multiple perspectives. We conclude by emphasizing the potential impact of new media in ushering in hybrid digital products that merge means of representation traditional to filmmaking and cartography.
\end{abstract}

SC. Why would a filmmaker like you involved in exploring globalization through film be interested in maps and cartography?

AB. In my view cartography and cinema have a similar problem at heart: how can we represent the world in a meaningful and engaging way? These representations can be made with many kinds of information - fragments of the world - including information in the form of scientific data, or about spatial and temporal relationships, cultural practices, and even individual perceptions or emotions. These two disciplines seemingly address the challenge of constructing representations of the world from different angles, and I am interested in exploring them. More specifically, I am interested in exploring how the combination of these two practices could be complementary in terms of understanding and representing globalization, which is a significant focus of the work of many contemporary filmmakers, including myself.

SC. So, you are interested in cartography as a domain that could help you to better represent globalization in your films. Could you elaborate a bit?

AB. My desire to represent globalization is perhaps my way of saying that I want to find ways of making sense what is happening in the world today, and I think that cartography might be able to help me do that. Globalization is a name for a collection of phenomena that characterize and influence contemporary politics, business, and everyday life. Globalization operates at multiple scales, from the personal to the global, and impacts both humans and our environment. It spans issues ranging from the influence of transnational organizations, to global labor and global capital movements, to deregulation and privatization, oil, scarce resources, intellectual property rights, China, containerized shipping, export processing zones, and anti-globalization movements (Zaniello, 2007: 2). Globalization and its associated flows of capital, people, and objects is challenging to make sense of. It challenges traditional forms of representation and resistance (Jameson, 1991).

Film theorist Holly Willis suggests an explicit connection between films and maps in the context of globalization. She frames films as a type of 'map' that may be able to capture the increasing complexity of the world in a different way than more literal cartographic representations. This desire for alternative or hybrid forms of mapping stems from a dilemma of representation: "How 
do you 'map' a global economy, a vast military industrial complex, or the convergence of gigantic corporations? How do you chart multinational banking and stock exchanges, or the increasingly powerful web of bureaucratic control?" (Willis, 2005: 74-75). Those are the questions I hope cartography could help me to address. Maybe, as Willis suggests, filmmaking and cartography could be helpful to each other.

SC. These questions have indeed been addressed through maps, even if globalization is not a major topic in cartography. For instance, the map The U.S. Oil Fix by Brooke Singer shows the oil resources that the U.S. exploits from the rest of the world, illustrating, simultaneously, "dependency and global pillage" (Abramsky, 2006: 130). Abramsky uses this map to discuss the negative impact a global energy crises might have on workers in the U.S.. There are several other examples of maps that address global issues ${ }^{1}$. In many cases, maps often take a big picture point of view depicting, for example, the structure of organizations, workings of the global economy, or the transnational flux of money and people. It is my sense that cinema often deals with globalization at a much finer scale: a neighborhood, a community, a family, or even an individual. Do you think that in the process of mapping globalization cartography could learn from cinema in terms of how to represent the human consequences of globalization, while cinema could learn from cartography to capture the essence of its global structure?

AB. This polarization based on scale could certainly serve as a point of departure to explore the potential of combining the two disciplines to provide a better understanding of the links between global structures and their human counterparts. This polarization resonates with strategic and tactical forms of representation. Strategic representations present the big picture, illustrating interconnections. Tactical representations, meanwhile, operate from the ground, such as out of personal experiences or specific places (de Certeau, 1984). While strategy - a view from above, may seem to always trump tactics - views from below, tactical practices provide useful information of their own. In fact, J.J. King (Abrams and Hall, 2006: 44-49) argues that maps representing large systems are not always useful. For instance, he says, although the World Government Map by Bureau d'Études, which traces relationships between entities like the World Bank, the IMF, banks, and other organizations, represents important information, its significance may remain opaque to an outsider. An alternative practice to mapping complex entities as a whole, he suggests, is working from nodes. Each node - a worker at the World bank, a farmer in Argentina, a small car manufacturing plant - knows its own reasons for existence and can provide a specific, and perhaps more accessible, views of the system. Some mapping and filmmaking techniques take this strategy to heart, using tactical methods to build a strategic view. In power mapping and participatory video, for example, participants work together to develop a larger view of the world based on their everyday experiences. Though these exercises can result in finished maps and films, it is the tactical practices of mapping and making themselves that are most valuable.

SC. Are you suggesting that the process of constructing a film or a map investigating globalization must be tactical in essence? In other words, does it require the mapmaker or the

\footnotetext{
${ }^{1}$ For more examples of maps that deal with globalization see Mogel and Bhagat's Atlas of Radical Cartography (2007), Abrams and Hall's Else/Where: Mapping New Cartographies of Networks and Territories (2006), as well as the newspaper Le Monde Diplomatique, in which maps representing global issues designed by cartographer Philippe Rekacewicz and others appear recurrently.
} 


\section{filmmaker to go to the field and collect data herself?}

AB. Indeed, to tell a global story, a filmmaker - or a cartographer - must make a journey through the global web. But this journey can be done at many different scales and in many different ways, all of which can be valuable. It can be done by following the flow of international monetary trading on a computer screen, crossing borders with immigrants, or sitting in on the meetings of the powerful World Trade Organization. There are many ways to navigate through these systems, and by choosing a particular route - perhaps the one she herself took, or perhaps the story or data of another - the filmmaker or cartographer provides a guide.

A single document might move between local and global perspectives. Films, in particular, as slippery, dense, emotional spatial representations, may provide some view to the relationship between, or side-by-side existence of, abstract global events and concrete local effects. For instance, my non-fiction film spring wind will bring life again (Amelia Bryne, 2007) can be seen as a kind of 'map' of contemporary Beijing, which proceeds as a zoom from the global, to the city, to the individual (Figure 1). Specifically, the first part of the film focuses on the world at large and the economic and political relationship between the U.S. and China, the second reveals the city itself, focusing on everyday categories like traffic, crowds, restaurants, grocery stores, bars, tv, etc.. The final section of the film tells the story of a woman who, like hundreds of thousands of others, was displaced from the center of the city (to a new suburb) when her home was torn down in the effort by the government to modernize Beijing and present it for the 2008 Olympics. Obviously this type of cinematographic work can't be done without some fieldwork, without a tactical approach.

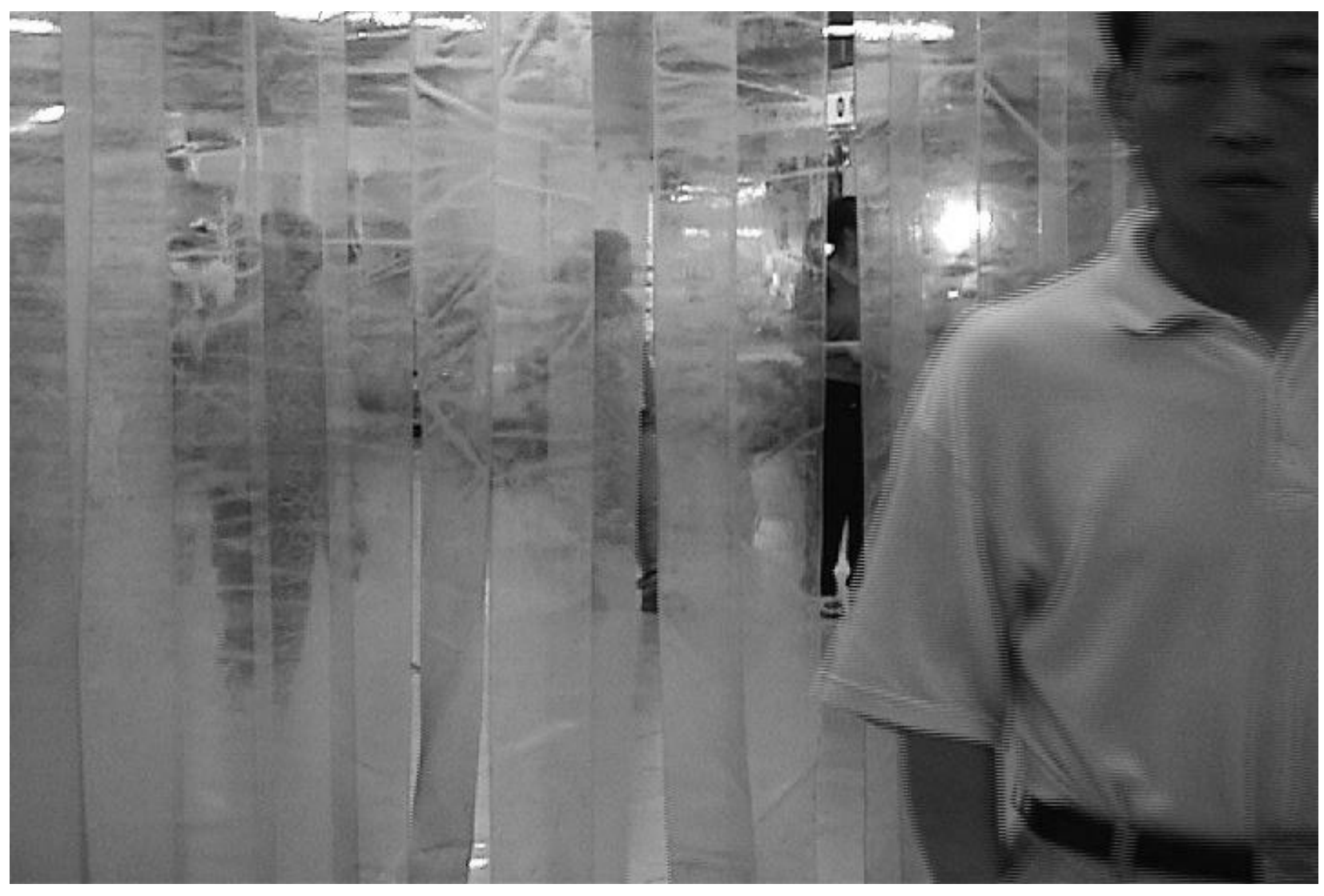


Figure 1. Still frame from spring wind will bring life again (Amelia Bryne, 2007).

SC. If I try to synthesize what you are saying, I can identify three major components in your approach to globalization. The first one is the tactical dimension and the fieldwork it implies. The second one is the scale crossing from the global to the personal. The third one is the storytelling dimension, the narrative that brings together these pieces and conveys them to your audience.

This combination is certainly not common in cartography, but it appears in some maps. For instance, in From South to North Lize Mogel combines images of maps of different scales of San Francisco, the Panama Canal, and North America. Mogel does this to emphasize the idea that the Panama Canal brought San Francisco onto the global map in 1914 by making it 9,000 miles closer to the Atlantic Ocean, and to its intensive economic exchanges (see Figure 2). Sarah Lewison (2007) uses this map to tell the story of the consequences the canal had on local communities in Panama in terms of unemployment, corruption, foreign occupation of land, and environmental disasters. Through her reading of the map, Lewison emphasizes the links between global activities, and local consequences: "Look again at Mogel's map to see how close the Bay area is to the Nunavut Territories. How near are San Francisco Bay refineries to the-off-the-map struggles in Nigeria, Bolivia and Ecuador over local control of oil?" (Lewison, 2007: 92). Through Lewison's narrative the meaning of Mogel's map becomes obvious, revealing the complexity of its structure and of the phenomena it represents. In addition, the local / global relationships explored in this map become clear by echoing this relationship in the text.

This illustrates quite well the idea that mapping globalization requires not only "a global sense of the local, [and] a global sense of place” (Massey, 1994: 156), but also a compelling narrative. I believe cartography has a lot to learn from cinema in this domain.
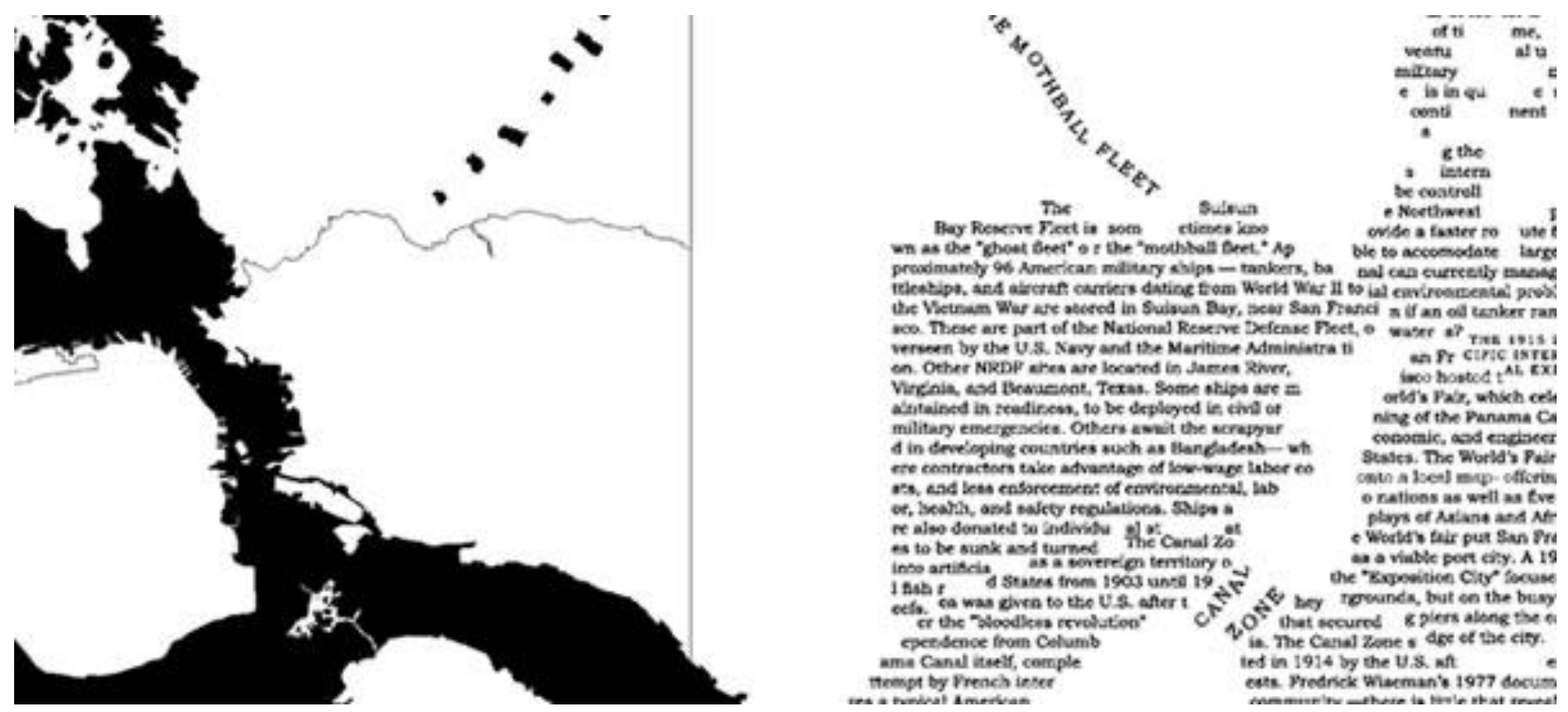

Figure 2. From South to North by Lize Mogel (2006) (Courtesy of the artist).

AB. Are you suggesting that cartography is not very good at telling stories? 
SC. Cartography is very good at representing data and conveying information, but it could certainly be better in terms of storytelling. That said, maps tell all kinds of stories. In a figurative sense, maps tell stories because they are not what they seem: maps are not an objective and neutral representation of reality. In a literal sense, maps tell stories related to the places they represent: how to get there, who lives there, how the place has changed over time. The simple journey of the eye on the map can even be considered as a narrative act, or an actualization of one scenario among multiple possibilities (Agez, 1996). Maps tell stories and stimulate the imagination of the audience. They can trigger personal impressions and memories of places or of other maps (Jacob, 1992). Yet, beyond these general statements, there are some major differences between different types of maps in terms of their storytelling potential. For instance, a technical map of a ventilation system mainly designed for efficient management of the system might leave little room for stimulating the imagination and the emotions of the user. On the other hand, an itinerary map can take the audience from one point to another, and provide a linear sense of movement through space, somewhat like a film's linear movement from start to finish.

Overall, atlases - as collections of maps - have a stronger storytelling potential, comparable to novels (Wood, 1987). They often allow the user to create personal associations, which can extend the meaning of maps beyond what their authors may have intended (Jacob, 1992). The user simultaneously becomes the author and the spectator of his own fictions in his interaction with the maps of an atlas. A road atlas can stimulate memories of a trip, or the pleasure of planning and anticipating a future journey. In this sense, atlases, and maps in general, may be envisioned as both story stimulators, and storytelling mechanisms.

What is probably even more important in terms of the narrative and emotional potentials of maps is the context of their appearance. When maps appear in films, even a map that otherwise would have little storytelling potential can be transformed into a key narrative element. Here the same technical map of a ventilation system can become a dramatic narrative element in fighting a terrorist attack (Figure 3). Maps in films are embedded in a narrative process to which they contribute in return. A map in a movie is inherently narrative. Furthermore, in this context, the map becomes the link between the global structure (e.g. global terrorism) and its potential human consequences (e.g. multiple deaths). Through these types of combinations maps and films could work together to better capture the complexity of globalization and its impacts. Cartographers could certainly gain in terms of storytelling by looking at the way maps have been used by filmmakers. 


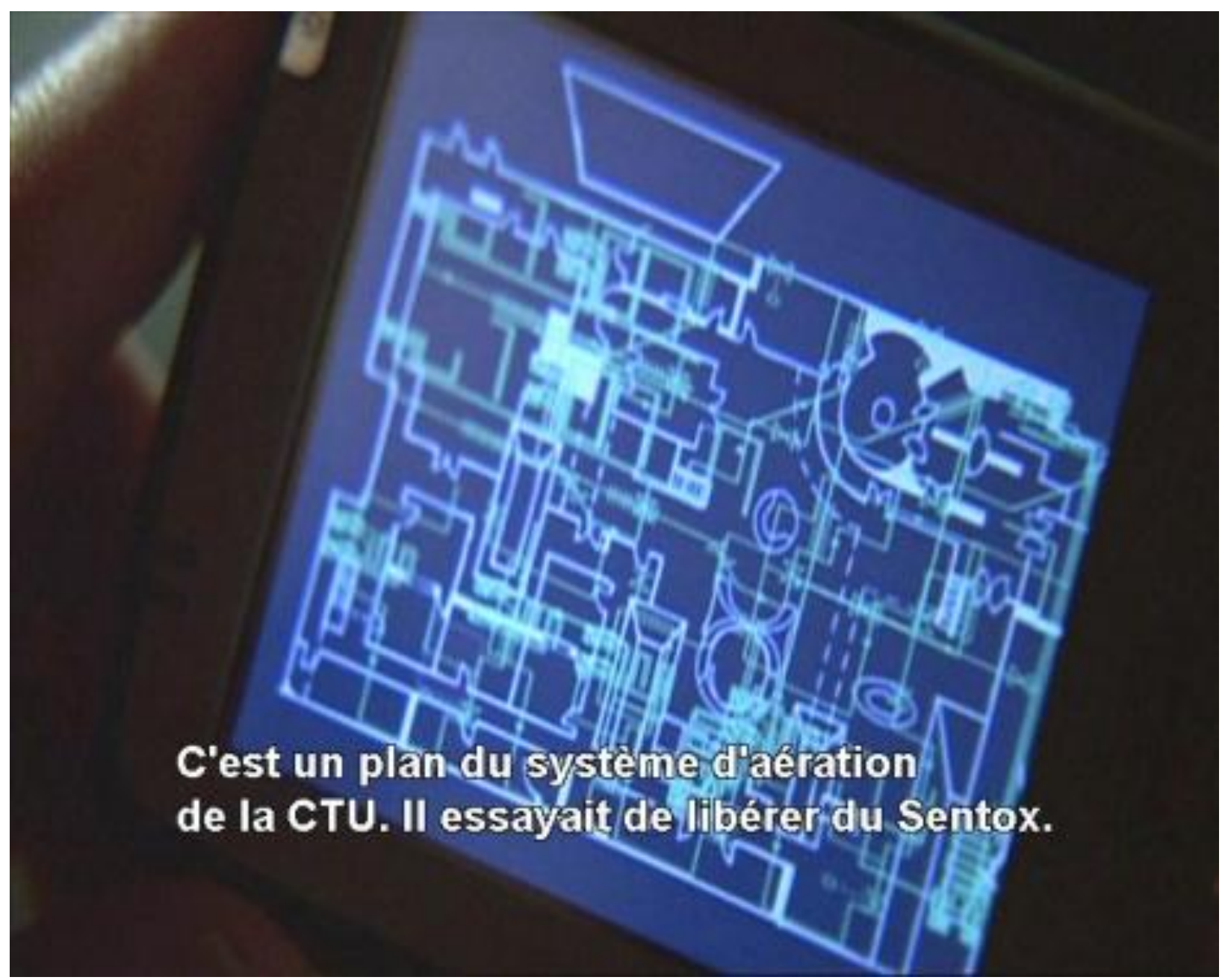

Figure 3. In this example from the TV series 24 hours (created by Joel Surnow \& Robert Cochran, season 5, episode 18.00-19.00), a technical map serves as a key narrative element to locate the terrorists' targets (See Joliveau, 2007).

AB. Is this practice of using maps in films to convey ideas of globalization common?

SC. The use of cinematic maps to convey notions of globality has been recurrent in the history of cinema. From Casablanca (Michael Curtiz, 1942), to Un capitalisme sentimental [A sentimental capitalism] (Olivier Asselin, 2008), there is a long history in cinema of embedding maps to convey ideas related to globalization. The classic film Casablanca (Michael Curtiz, 1942) opens with a series of maps that take the audience from a view of the entire globe down to a busy street in the city. The images of refugees fleeing the war that overlay this sequence show quite literally the global context of WWII with its dramatic consequences at the personal scale (see Conley, 2007).

More recently, in Un capitalisme sentimental (Olivier Asselin, 2008) maps were used to suggest the links between the global economy and the personal life of the main character: Fernande Bouvier. One of these maps includes a zooming effect that takes the audience from the body of Fernande Bouvier at the New York City Stock Exchange to the entire world in a few seconds (Figure 4). This move suggests the influence of strong global forces on Fernande's personal 
destiny. This type of cartographic effect is recurrent in contemporary cinema (see Caquard, 2009) and illustrates the power of maps to suggest notions of globalization. It also characterizes the potential for the combination of emotional and personal cinematographic narrative with cartographic strategies.
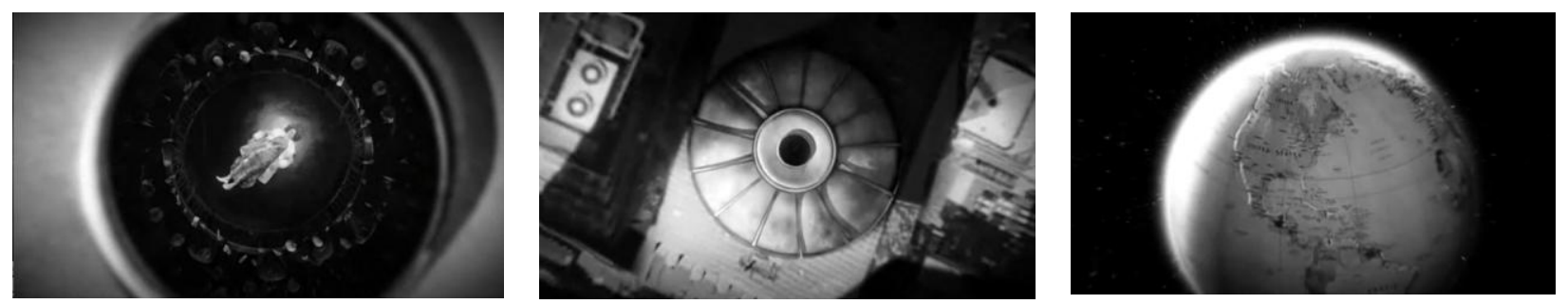

Figure 4. In Un capitalisme sentimental (Olivier Asselin, 2008), a zooming effect takes the audience from the body of Fernande Bouvier in New York City Stock Exchange to the entire world in a few seconds.

This practice also percolates through documentaries, which share with cartography an illusory sense of neutral point of view. Especially when dealing with issues of globalization documentaries can make an extensive use of cartography to develop their argument and reinforce their objectivity. An Inconvenient Truth (Davis Guggenheim 2006) with Al Gore uses compelling global maps and graphics. Through maps and the presentation of scientific data the film shows the links between human activities, environmental changes, and the impact of these on human life. The global scale of many of the maps emphasizes the global dimension of climate change. They also shape the movie as a global commodity formatted for a global audience and a global market. The technological dimensions of the very sophisticated maps included in the film also characterize recent dramatic changes in narrative cartography under the influence of new media.

AB. What do you mean exactly?

SC. I mean that maps, with the advent of digital tools, can now be dynamic, interactive, and animated in ways that increase their narrative potential. Some animated maps are very similar to films with dramatic tension and a storyline. But, the major change in terms of mapping globalization is probably in the appearance of virtual globes, such as Google Earth. With Google Earth one can, in the space of a few seconds, zoom in from an image of the entire world to one's own community. Maybe even more interesting is that people can tag these reference globes with personal information, like pictures or videos associated with specific places. In this context, cartographic narratives are changing very quickly. We are moving from meta-narratives in which the map provides the ultimate reference, to some hybrid form of narrative in which official narratives conveyed by maps like Google Earth are mixed with very personal, often local, stories.

Again, this change is illustrated by the practice of communities mapping themselves by marking or geo-tagging digitally-based maps such as Google Earth with personal reference points. Local stories can now be mapped at a global scale. This convergence between personal and universal creates a new environment that shapes the production and the distribution of geospatial narratives. These narratives are not necessarily better, but they enable citizens to represent their environment in new ways (see Nold, 2009). These stories can be more local, more personal, may be more emotional, and afford maps a greater tactical side in the representation of globalization. 
AB. New media have had a somewhat similar impact in cinema. Filmmaking is changing dramatically in terms of production, aesthetics, and distribution, providing new means of expression, and for exploring and critiquing globalization from above and below.

A number of new media uses of the moving image incorporate elements of mapping, making the boundary between the map and the film less clear, and approaching new narrative/spatial hybrids $^{2}$. Most grandly, visualization techniques like augmented and virtual reality, or exhibition spaces like IMAX theatres and geodesic domes, try to bring viewers literally into the space of cinema, or to dissolve the boundary between cinema space and physical space. The company, Elumenati, for instance, designs geodesic domes to help users, like scientists, or museum teams, visualize scenarios in a cinema-like space. These navigable cinema spaces can serve as platforms for both storytelling and problem solving.

New media artworks have also examined new ways of representing the relationship between space and time. In the Field-work @ Shinji project, Masaki Fujihata gathered a team of students to spend a few days interviewing, filming, and photographing people around a lake in Japan. The final piece, presented in a museum space and on the internet, gives a sense of what is happening in multiple places over a short period of time: a dense and vivid portrait of the lake (Shaw and Weibel, 2002: 424). Likewise, filmmaker Julie Talen's project 60 Cameras, incorporates footage shot by 60 individuals during the February 2003 demonstration against the Iraq war in New York City. Her film is a significant media representation of a notoriously undocumented event.

Throughout the piece, the screen shows feeds from different numbers of cameras, sometimes the full sixty appear, whereas other moments are presented from only a few points of view (Figure $5)$.

\footnotetext{
${ }^{2}$ For example, see the Murmur project, Masaki Fujihata's project Field-work @ Alsace, or the book Future Cinema: The cinematic imaginary after film (Shaw and Weibel, 2002).
} 


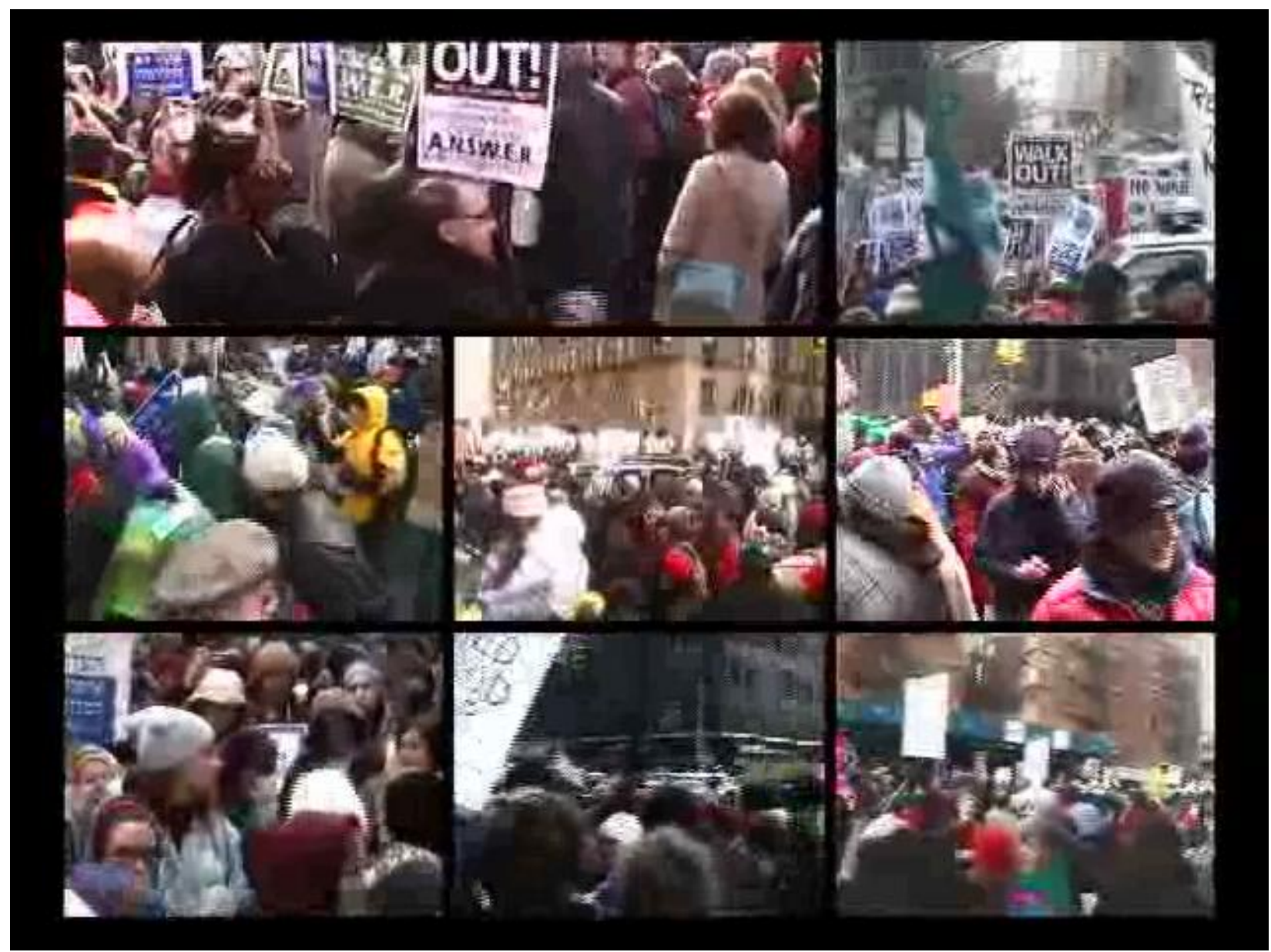

Figure 5. Still frame from 60 Cameras Against the War (Julie Talen, 2003) (Courtesy of the artist).

The film is meticulously edited, with the action recorded by the sixty cameras lined up in time, so that what the viewer sees on each part of the screen is happening at approximately the same moment. While the simultaneity of events can be represented in traditional cinema through montage - switching from location to location - both Field-work @ Shinji and 60 Cameras intensify the use of space, opening up the possibility for showing not just two or three events happening at the same time, but tens or hundreds.

SC. Perhaps the representation of multiple events simultaneously - and of multiple perspectives in general - is another key element in terms of ways that cinema and cartography might better represent globalization. ... How would you now define the relationship between our two fields?

AB. I think that the complementarities between cinema and cartography for mapping globalization go beyond a simple combination of techniques and concepts from each discipline. The solutions for addressing and representing the complexity of the issues around globalization are certainly not all technological, though new media provides some powerful options. The examples of new media artworks discussed here - a few among many - meld elements of cinema and maps with unconventional interfaces, adding additional means of navigation, geographic significance, or density of information. Perhaps these hybrids are the beginning of new 
crossovers between films and maps, ones that might be used to uncover and present other aspects of globalization. Further, as we have both said, both cartography and cinema are changing dramatically under the influence of new media and new technologies. In some ways, they seem to be moving closer to each other, sharing an increasing number of goals, concepts, technologies, and techniques. In the future, maybe there will be no "cinema" or "cartography" per se, but only tendencies towards these poles and others. While some maps may remain maps, and some films may remain films in the traditional sense, might we see an increasing amount of hybrid practices?

\section{References:}

Agez, F. (1996). La carte comme modèle des hypermédias, Artifices 4, langages en perspectives, http://www.ciren.org/artifice/artifices_4/agez.html (Accessed Sept. 2009)

Abrams J. and P. Hall (eds), (2006). Else/Where: Mapping - New Cartographies of Networks and Territories, University of Minnesota Press, Minneapolis.

Abramsky, K. (2006). Struggles, Over Transition: Emancipating energy?, In Mogel, L. and Bhagat, A. (Eds.), An Atlas of Radical Cartography

Caquard S. (2009). 'Foreshadowing Contemporary Digital Cartography: A Historical Review of Cinematic Maps in Films', The Cartographic Journal 46 (1): 46-55.

De Certeau, M. (1984). Spatial stories, In The practice of everyday life, University of California Press, Berkeley, Calif.

Conley, T. (2007). Cartographic cinema, University of Minnesota Press, Minneapolis.

Jacob, C. (1992). L'empire des cartes - Approche théorique de la cartographie à travers l'histoire, Bibliothèque Albin Michel Histoire, Albin Michel, Paris.

Jameson, F. (1991). Postmodernism, or, the cultural logic of late capitalism, Duke University Press, Durham, NC.

Joliveau T. (2007). Inventaire des techniques géonumériques dans 24 heures chrono, Blog Monde Géonumérique, http://mondegeonumerique.wordpress.com/2007/02/09/essai-dinventairedes-techniques-geonumeriques-dans-24-heures-chrono/ (Accessed Sept. 2009).

Lewinson, S. (2006). Our Land is Changing - Soon Yours will be Too, In Mogel, L. and Bhagat, A. (Eds.), An Atlas of Radical Cartography

Massey, D. (1994). Space, place, and gender, University of Minnesota Press, Minneapolis.

Mogel, L. and Bhagat, A. (2006). An Atlas of Radical Cartography, Journal of Aesthetics and Protest Press, Los Angeles, CA.

Nold, C. (2009). Emotional Cartography - Technologies of the Self, Published under a Creative Commons Licence, www.emotionalcartography.net (Accessed Sept. 2009)

Shaw, J. and Weibel, P. (2002). Future Cinema: The cinematic imaginary after film, MIT Press, Cambridge, MA.

Willis, H. (2005). New digital cinema: Reinventing the moving image, Wallflower Press, London. 
Wood, D. (1987). "Pleasure in the idea / The atlas as narrative form", Cartographica 24(1): 2446.

Zaniello, T. (2007). The cinema of globalization: A guide to films about the new economic order, Ithaca, ILR Press, New York.

\section{Films and Art Works:}

24 hours

http://www.fox.com/24/

60 Cameras Against the War (Julie Talen, 2003, USA, $27 \mathrm{~min}$ )

http://www.glimpseculture.com/pages/60catw.php

An Inconvenient Truth (Davis Guggenheim, 2006, USA, $100 \mathrm{~min}$ )

http://www.climatecrisis.net/

Un Capitalisme Sentimental (Olivier Asselin, 2008, Canada, 95 min)

http://www.uncapitalismesentimental.com/

Casablanca (Michael Curtiz, 1942, USA, 102 min)

Elumenati

http://www.elumenati.com/

Google Earth

http://earth.google.com/

Masaki Fujihata's Field-Works

http://www.field-works.net/

Murmur

http://murmurtoronto.ca/

spring wind will bring life again (Amelia Bryne, 2007, USA, 42 min)

http://www.misociety.net/project/spring-wind-will-bring-life-again/ 